\title{
New Thermoplastic Damping Polymeric Materials Based on Ethylene-Vinyl Acetate
}

\author{
ALEXEY VOLOTSKOY, YURIY YURKIN*, VALERIY AVDONIN \\ Vyatka State University, Building Structures and Machines Department, 36 Moskovskaya Str., 610000, Kirov, Russia
}

\begin{abstract}
This article is devoted to the problem of working out of damping polymer materials which are effective in the wide temperature and frequency range. In the modern world, work is being carried out to create damping polymer composite materials (DPM) from which it is possible to manufacture protective elements and parts of engineering structures of reduced vibration excitability. Existing DPM have a narrow temperature range, within which effective vibration absorption is observed, moreover, most of them go through a vulcanization stage, which increases the cost of the final product, has a harmful effect on environment and allows limited recycling of waste. One of the ways to solve this problem is to replace traditional rubber vibration-absorbing materials with thermo-elastoplasts (TEP). The most promising polymer for TEP is ethylene vinyl acetate (EVA), which has high damping properties, oil resistance and relative incombustibility. In this regard, experimental studies were conducted to establish the patterns of influence of the type and concentration of structure-forming components (plasticizers, fillers, modifiers) on the dynamic mechanical properties of TEP based on EVA in order to develop a new DPM effective in a wide temperature range. The leading method to investigate this problem is a method of dynamic mechanical analysis which allows to get information about changes of mechanical characteristics under mechanical load and controlled temperature and frequency. With the help of detected patterns it was possible to determine type of plasticizer which significantly decreases glass temperature of EVA. The percentage ratio of EVA/plasticizer system is stated, and the type of plasticizer at which the maximum of mechanical losses takes over greater values is accordingly detected. It is revealed, that to work out DPM on EVA basis, which are effective in wide temperature range it is more preferable to add not less than $40 \%$ on volume basis inert fillers, such as talc or mica with addition of 5-10\% of carbon as the hardening additive. The kind of resin improving damping properties and raising rigidity of composites on EVA basis is defined. On the basis of the research, a material was developed which has the following properties: the maximum value of tan $\delta$ is at least 0.45 at a temperature of plus $5^{\circ} \mathrm{C}$ (oscillation frequency $10 \mathrm{~Hz}$ ); width of the temperature interval within which tan $\delta$ is not less than 0.3 from minus 40 to plus $50^{\circ} \mathrm{C}$ (oscillation frequency $10 \mathrm{~Hz}$ ); conditional tensile strength of not less than $10 \mathrm{~kg} / \mathrm{cm}^{2}$, cold resistance up to minus $50^{\circ} \mathrm{C}$.
\end{abstract}

Keywords: Damping, Dynamic mechanical properties, Dynamic mechanical analysis (DMA), Ethylenevinyl acetate (EVA), Elastic properties

\section{Introduction}

The most effective materials reducing vibration in designs are polymeric composites. The highest damping properties at such materials are displayed at temperatures at which polymer of which the composite consists, is near to glass transition temperature [1]. Within the yielded temperature polymers have pronounced dissipation of mechanical energy into heat because of occurrence of coordinated movements of molecular chains [2,3]. Efficiency of polymeric composites capturing energy of fluctuations, in comparison with other types of composites (ceramic, metal etc.) is caused by that polymers have wider transitive area from high-elasticity condition to vitreous in which there are maximum mechanical losses. This interval of temperatures defines a range of the most effective application of damping polymeric composites. The ratio of $E^{\prime \prime} / E^{\prime}$, named as $\tan \delta$ (loss tangent), is used as an assessment of the ability to dissipate energy by elastomers, where $E^{\prime \prime}$ and $\mathrm{E}^{\prime}$ are the loss modulus and storage modulus, respectively. High - performance damping materials should meet the requirement

\footnotetext{
*email:yurkin@vyatsu.ru
} 
of $\tan \delta>0.3$ over a broad temperature range of at least $60-80^{\circ} \mathrm{C}$. However, polymers display damping properties in insufficiently wide interval of temperatures $-20 \div 30^{\circ} \mathrm{C}$ near to their glass transition temperature. There are some methods of modification of dynamic properties of polymers [4]. One of such methods is addition of various kinds of fillers to a polymeric matrix. An important criterion of damping materials efficiency is width of temperature site, in which $\tan \delta$ should make not less than 0.3. Frequently filled polymeric composites have enough wide interval of operating temperatures, however angle tangent of mechanical losses is not always above 0.3 in the yielded interval. One of ways to increase damping properties of polymers is addition of modifiers - resins [5].

In work [6] research of damping properties of polymeric materials on the basis of ethylene-vinyl acetate at addition of polylactic acid is presented. Addition of the yielded polymer is noticed to expand a temperature range of effective damping [6]. However received materials capture energy in two narrow temperature areas corresponding to two temperature transferrings, but do not possess this ability in intermediate temperature area. In work [4] damping properties of material which has similar composition at addition modifiers in the form of various resins in it are studied. Authors [4] notice, that the yielded modifiers allow to raise $\tan \delta$ and to expand temperature range of effective damping. A general disadvantage of polymeric materials studied in works $[4,6]$ is that they extinguish vibration only in the area of positive temperatures efficiently, and also pass a stage of vulcanization in the course of preparation of laboratory samples. In work [7] to extend area of effective damping authors added the second polymer as a acrylonitrile butadiene rubber to ethylene-vinyl acetate. However the received material is ineffective from the point of view of decrease in vibrating loading in the area of negative temperatures and passes a stage of vulcanization in the process of laboratory samples preparation.

In all studied researches $[4,6,7]$ ethylene-vinyl acetate with percentage vinyl acetate links not less than $40 \%$ which can be referred to rubbers according to its characteristics was used as a polymeric basis. Thus, to work out polymeric materials which are effective in wide temperature range it is necessary to replace rubber polymeric materials to thermoelastoplastics. The most optimal polymer for working out of damping materials on the basis of TEP is ethylene-vinyl acetate containing $28 \%$ of vinyl acetate links.

In this regard the following tasks were set:

1. To determine patterns of influence of kind and concentration of structure-forming components (plasticizers, fillers, modifiers) on dynamic mechanical characteristics of TEP on the basis of ethylenevinyl acetate;

2. To choose the most suitable structure-forming components to work out new DPM, which is effective in wide temperature range from minus $40^{\circ} \mathrm{C}$ to plus $40^{\circ} \mathrm{C}$ on the basis of determined patterns.

\section{Materials and methods}

\subsection{Materials}

Properties of ethylene-vinyl acetate depend on percentage of vinyl acetate links in it. Basic characteristics of ethylene-vinyl acetate with various content of vinyl acetate (VA) are resulted in table 1.

Table 1. Properties of ethylene-vinyl acetate

\begin{tabular}{|c|c|c|c|}
\hline Mark & Vinyl acetate content, $\%$ & Melting point, ${ }^{\circ} \mathrm{C}$ & Tensile strength, MPa \\
\hline EA19150 & 19 & 80 & 7 \\
\hline ES28005 & 28 & 72 & 13.5 \\
\hline EA40055 & 40 & 53 & 4.8 \\
\hline
\end{tabular}

Ethylene-vinyl acetate with VA content of 19 and $28 \%$ have high melting point, however EVA with VA content of $19 \%$ possesses low ultimate tensile strength. Ethylene-vinyl acetate with VA content of $40 \%$ has the lowest characteristics of hardness and melting point. Thus, ethylene-vinyl acetate LG EVA ES 28005 («LG Chem», South Korea) with VA content of $28 \%$ was chosen as a polymeric basis. 
Dioctylphthalate («BINAGroup», Russia) of GOST 8728-88; chlorine-paraffin ChP-470 («Vitahim», Russia) technical specifications 2493-379-05763441-2002; oil industrial I-40 («OILRIGHT», Russia) GOST 20799-88 were chosen as plasticizers which are necessary for improvement of blend workability. Volume content EVA/ plasticizer - 80/20; 60/40.

Dioctylphthalate is the most often used plasticizer to work out damping materials. However the yielded plasticizer has negative impact on human health. In the yielded research dioctylphthalate is used for ethylene-vinyl acetate plasticization, to study possibility of its replacement by other inexpensive and less harmful plasticizers: industrial oil or chlorine-paraffin. Besides, chlorine-paraffin and industrial oil have various polarity. The yielded factor will allow to estimate influence of polarity of plasticizer on dynamic properties of ethylene-vinyl acetate.

Two types of resins were used as modifiers: alkyl phenol-formaldehyde resin SP-1045 («SI Group», France); glycerol esters of rosin («ORGSINTEZ», Russia) technical specifications 2435-063-057885762008.

The form of filler particles essentially influences on dynamic properties of damping polymeric composites. Therefore as fillers were used: mica («GEOKOM», Russia) with technical specifications 5725-005-40702684-2001, talc («GEOKOM», Russia) with technical specifications 5727-00140705685-2001, carbon black P-803 («Tuymazytehuglerod», Russia) GOST 7885-86 with scaly, plate and spherical forms of particles accordingly. All damping polymeric materials depending on degree of their filling by disperse fillers are divided in two groups: little filled and highly filled composites [8]. The first possess raised deformability, the second have higher elastic modulus and so hardness concerning unfilled polymer. Proceeding from these conditions $40 \%$ filler content in volume basis were accepted as a part of a composite.

Calcium carbonate («GEOKOM», Russia) was applied as a filler reducing price. Volume content of filler as a part of a polymeric composition was $50 \pm 1 \%$.

Compositions and marks of investigated composites are resulted in tables 2-4.

Table 2. Compositions and marks of investigated composites

\begin{tabular}{|c|c|c|c|c|}
\hline \multirow{2}{*}{ Mark of a blend } & Polymer & \multicolumn{3}{|c|}{ Plasticizer } \\
\cline { 2 - 5 } & EVA & $\begin{array}{c}\text { Oil industrial } \\
\text { (OI) }\end{array}$ & $\begin{array}{c}\text { Dioctylphthalate (DOP) } \\
\text { Chlorine-paraffin } \\
\text { (ChP) }\end{array}$ \\
\hline & \multicolumn{4}{|c|}{ Content in percentage in volume } \\
\hline EVA & 100 & - & - & - \\
\hline EVA/OI & 80 & 20 & - & - \\
\hline EVA/OI & 60 & 40 & - & - \\
\hline EVA/DOP & 80 & - & 40 & 20 \\
\hline EVA/ChP & 60 & - & - & 40 \\
\hline EVA/ChP & 80 & - & - & - \\
\hline
\end{tabular}

Table 3. Compositions and marks of investigated filled composites

\begin{tabular}{|c|c|c|c|c|c|}
\hline & \multicolumn{5}{|c|}{ Mark of a composite } \\
\hline System component & Without filler & $\begin{array}{c}\text { EVA/ChP 60/40 } \\
\text { mica }\end{array}$ & $\begin{array}{c}\text { EVA/ChP 60/40 + } \\
\text { talc }\end{array}$ & $\begin{array}{c}\text { EVA/ChP 60/40 + } \\
\text { carbon black }\end{array}$ & $\begin{array}{c}\text { EVA/ChP 60/40 } \\
+ \text { calcium } \\
\text { carbonate }\end{array}$ \\
\cline { 2 - 6 } & \multicolumn{7}{|c|}{ Content in percentage in volume } \\
\hline EVA & 60 & 36 & 36 & 36 & 36 \\
\hline ChP & 40 & 24 & 24 & 24 & - \\
\hline Mica & - & 40 & - & - & - \\
\hline Talc & - & - & 40 & 40 & - \\
\hline Carbon black & - & - & - & - & 50 \\
\hline Calcium carbonate & - & - & - & & - \\
\hline
\end{tabular}


Table 4. Compositions and marks of investigated composites modified by resins

\begin{tabular}{|c|c|c|c|c|c|}
\hline \multirow[t]{2}{*}{ Mark of a blend } & \multirow{2}{*}{$\begin{array}{c}\text { Polymer } \\
\text { EVA, } \\
\text { m.p }\end{array}$} & \multirow{2}{*}{$\begin{array}{c}\text { Plasticizer } \\
\text { ChP } \\
\text { m.p }\end{array}$} & \multirow{2}{*}{$\begin{array}{c}\text { Filler } \\
\text { Calcium } \\
\text { carbonate, } \\
\text { m.p }\end{array}$} & \multicolumn{2}{|c|}{ Modifier } \\
\hline & & & & $\begin{array}{l}\text { Alkyl phenol- } \\
\text { formaldehyde resin } \\
\text { (APFR), } \\
\text { m.p }\end{array}$ & $\begin{array}{l}\text { Glycerol esters of rosin } \\
\text { (GER), } \\
\text { m.p }\end{array}$ \\
\hline Without resin & & 100 & 241 & - & - \\
\hline APFR 10 & & 90 & 233 & 10 & - \\
\hline APFR 20 & & 80 & & 20 & - \\
\hline APFR 30 & & 70 & & 30 & - \\
\hline GER 10 & & 90 & 237 & - & 10 \\
\hline GER 20 & & 80 & & - & 20 \\
\hline GER 30 & & 70 & & - & 30 \\
\hline
\end{tabular}

\subsection{Manufacturing of samples}

Polymeric blends were made by means of laboratory mixer ZL-1.0 ( $F$ Fenix», Russia) with tangential rotors. Originally polymer was being mixed at temperature $120^{\circ} \mathrm{C}$ at speed of $44 \mathrm{rpm}$ during 20 minutes. Further polymer was mixed with plasticizer, filler and modifier were added, and then it was rolled on rollers until material of a homogeneous thickness was received.

\subsection{Methods of research}

\section{Dynamic mechanical analysis (DMA)}

DMA of experimental samples in the form of a disk with thickness of $2 \mathrm{~mm}$ was made by with use of device Netzsch DMA 242 C according to ASTM D4065-12 «Standard Practice for Plastics: Dynamic Mechanical Properties: Determination and Report of Procedures». Dynamic modulus of elasticity and $\tan \delta$ was defined in temperature range from $-80^{\circ} \mathrm{C}$ to $+40^{\circ} \mathrm{C}$ at frequency of 1 and $10 \mathrm{~Hz}$.

\section{Test for cold resistance}

Samples having size $5 \times 15$ and with thickness about $2 \mathrm{~mm}$ were placed for 30 minutes in a cold storage room. After this time each of samples, not being taken out from a cold storage room, was being bent on an arch of a template with radius of $250 \mathrm{~mm}$ during 2 hours. Temperature at which there was a first crack on the sample, was marked. Temperature range at which the test for cold resistance was conducted, was from $0^{\circ} \mathrm{C}$ to $-70^{\circ} \mathrm{C}$.

\section{Results and discussions}

\subsection{Influence of type and plasticizer content on dynamic properties of ethylene-vinyl acetate}

Efficiency of plasticizers is defined by means of their compatibility with polymer. For complex analysis of dynamic properties of a binary blend "polymer-plasticizer" plasticizers of various polarity were chosen. DOP and ChP are polar plasticizers. Industrial oil I-40 can be referred to weak-polar paraffin petroleum oils as alkane fraction dominates in the structure of a molecule of the yielded oil. It is possible to estimate the degree of polarity of substances quantitatively by means of solubility parametre (Table 5).

Table 5. Solubility parameter of EVA, OI, DOP, ChP [9-11]

\begin{tabular}{|c|c|c|c|c|}
\hline Indicator & EVA & OI & DOP & ChP \\
\hline Solubility parametre, $\left(\mathrm{MJ} / \mathrm{m}^{3}\right)^{0.5}$ & $\approx 17.5$ & $\approx 16.1$ & 18.2 & 19.5 \\
\hline
\end{tabular}



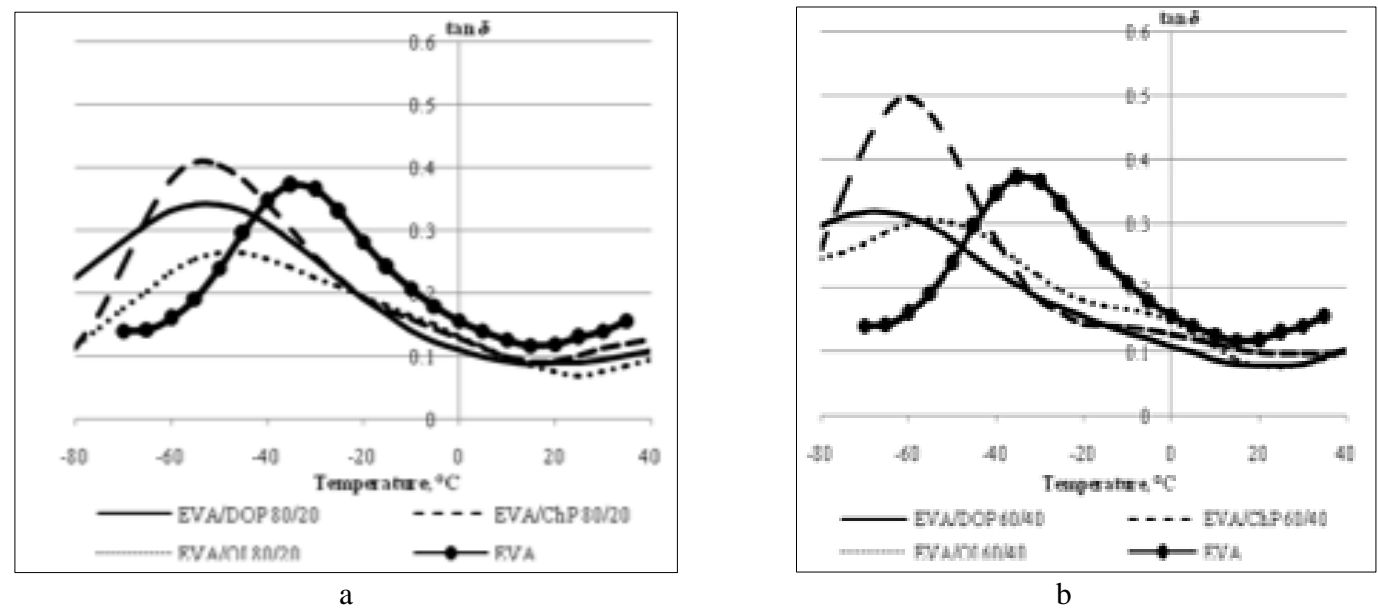

Figure 1. Comparison of $\tan \delta$ : a. - EVA/plasticizer 80/20; b. - EVA/ plasticizer 60/40

At addition of plasticizer into initial polymer there is a glass transition temperature displacement $\left(\mathrm{T}_{\mathrm{g}}\right)$ aside lower temperatures. For example, DOP and $\mathrm{ChP}$ at frequency of $1 \mathrm{~Hz}$ move $\mathrm{Tg}$ of initial EVA to the field of negative temperatures on $19^{\circ} \mathrm{C}$, and OI on $13^{\circ} \mathrm{C}$ (Figure 1a). It is explained by the fact that plasticizers DOP and ChP in comparison with OI possess higher compatibility with EVA (Table 5). As a result $\mathrm{T}_{\mathrm{g}}$ EVA plasticized by $\mathrm{DOP}$ or $\mathrm{ChP}$ considerably displaces to the field of negative temperatures because of intensity reduction of intra-and intermolecular chain interactions [12].

Plasticizer influences not only on polymer $\mathrm{T}_{\mathrm{g}}$, but also on angle tangent of mechanical losses. For example, when OI or DOP are used as plasticizers the size of tan $\delta$ EVA at $1 \mathrm{~Hz}$ decreases on 0.109 and 0.031 accordingly. At the same time at plasticization of EVA by chlorine-paraffin the size $\tan \delta$ increases on 0.04 (Figure 1a). It can be caused by more intensive physical interaction "polymer- plasticizer" by means of Van der Waals' forces [4].
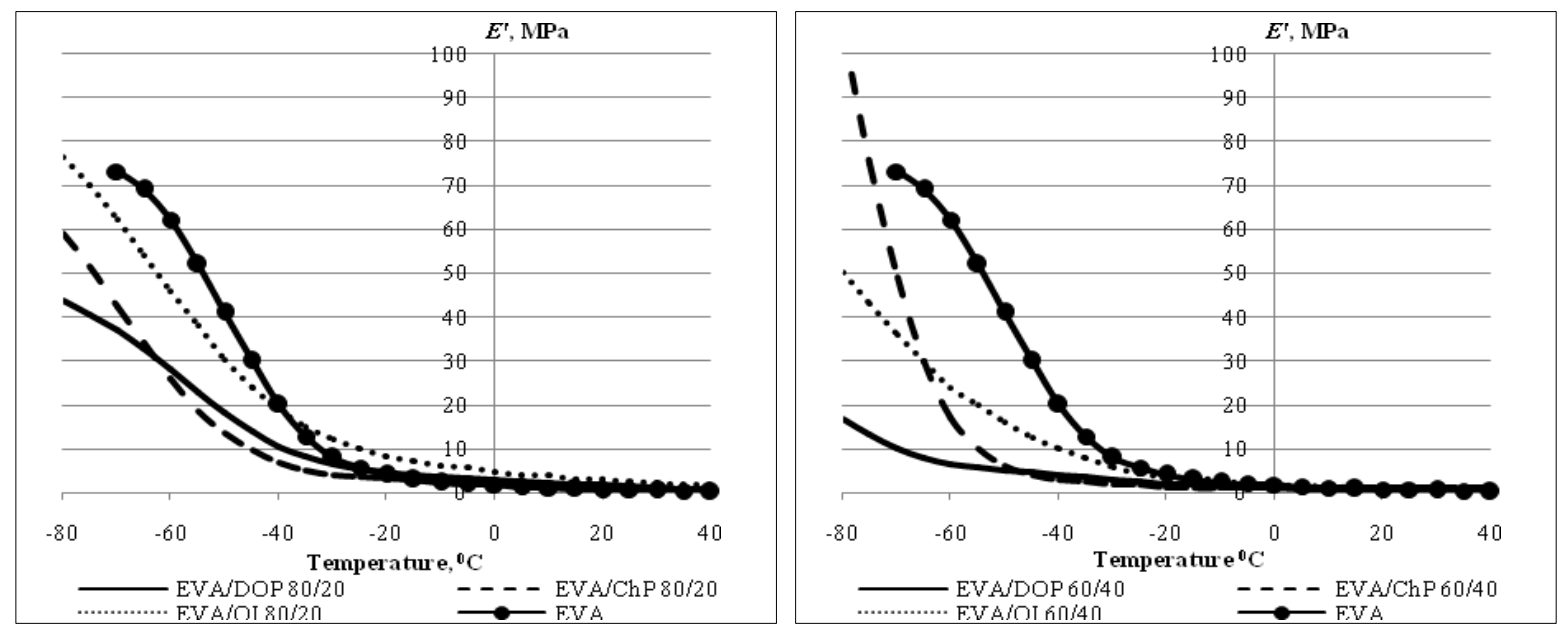

Figure 2. Comparison of $E^{\prime}$ : a. - EVA/ plasticizer 80/20; b. - EVA/ plasticizer 60/40.

Results of measurement of a complex modulus of elasticity $\left(E^{\prime}\right)$ for EVA with plasticizer content of $20 \%$ in volume basis are presented on Figure 2. At frequency of $1 \mathrm{~Hz}$ the greatest values $E^{\prime}$, are observed at ehylene-vinyl acetate plasticized by industrial oil (Figure 2a). Thus industrial oil, unlike DOP and $\mathrm{ChP}$, breaks interchain interactions in ethylene-vinyl acetate less. It means, that OI is limited by compatible plasticizer with EVA.

A similar situation is observed at strengthening of plasticizer as a part of a polymeric blend (Figure $1 \mathrm{~b}, 2 \mathrm{~b})$. The increase of plasticizer content in the blend displaces maximum of $\tan \delta$ predictably, observed in glass transition temperature range of a polymeric blend to lower temperatures. Industrial oil 
is limited in its compatibility plasticizer, and the presence of its content over $20 \%$ showed its migration. At the same time migrations of $\mathrm{ChP}$ and $\mathrm{DOP}$ were not revealed at all investigated concentrations. Thereupon we consider, $\mathrm{ChP}$ with content of $40 \%$ in volume basis is the most optimum plasticizer for developed damping material as there is not only a positive effect on dynamic properties of TEP, but it also reduces its combustibility. According to the next degree of plasticizer efficiency is dioctylphthalate. Use of industrial oil as plasticizer for EVA is inexpedient.

\subsection{Influence of filler type on dynamic properties of polymeric materials on the basis of ethylene- vinyl acetate}

Filler addition in plasticizer in polymer leads to interfacial layer formation, causing changes of $\mathrm{T}_{\mathrm{g}}$, width of peak $\tan \delta$ of polymer [13]. Unlike plasticizers, addition of fillers displaces maximum $\tan \delta$ towards positive temperatures (Figure 3a). For example, talc and mica at concentration of $40 \%$ move $\mathrm{T}_{\mathrm{g}}$ on $5^{\circ} \mathrm{C}$, and carbon black on $30^{\circ} \mathrm{C}$. This results from the fact that polymer has the limited mobility in interfacial layer and it is displayed in the form of effect "frosts" of a polymer part. Filler activity which can be quantitatively defined on specific surface of filler influences on processes of interfacial layer formation essentially. From all fillers presented in work, carbon black has the greatest specific surface (Table 6). In the result big amount of polymer comes into the interfacial layer that leads to thickness increase of boundary layer, to adhesion bond strengthening between polymer and filler particles, and also to significant displacement of $\mathrm{T}_{\mathrm{g}}$. [8].

Table 6. Characteristics of fillers

\begin{tabular}{|c|c|c|c|c|c|}
\hline \multicolumn{2}{|c|}{ Indicator } & \multicolumn{3}{c|}{ Filler } \\
\hline \multirow{2}{*}{$\begin{array}{c}\text { Specific } \\
\text { surface, } \mathrm{m}^{2} / \mathrm{g}\end{array}$} & Source & $\begin{array}{c}\text { Carbon } \\
\text { black }\end{array}$ & Talc & $\begin{array}{c}\text { Calcium } \\
\text { carbonate }\end{array}$ \\
\cline { 2 - 6 } & Kozeny-Carman Equation & 4.65 & 1.35 & 1.04 & 1.10 \\
\hline
\end{tabular}

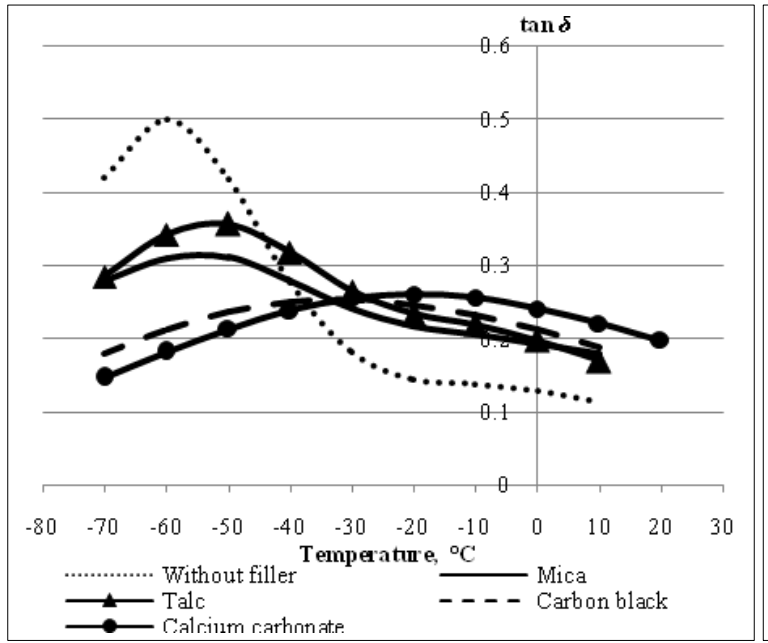

a.

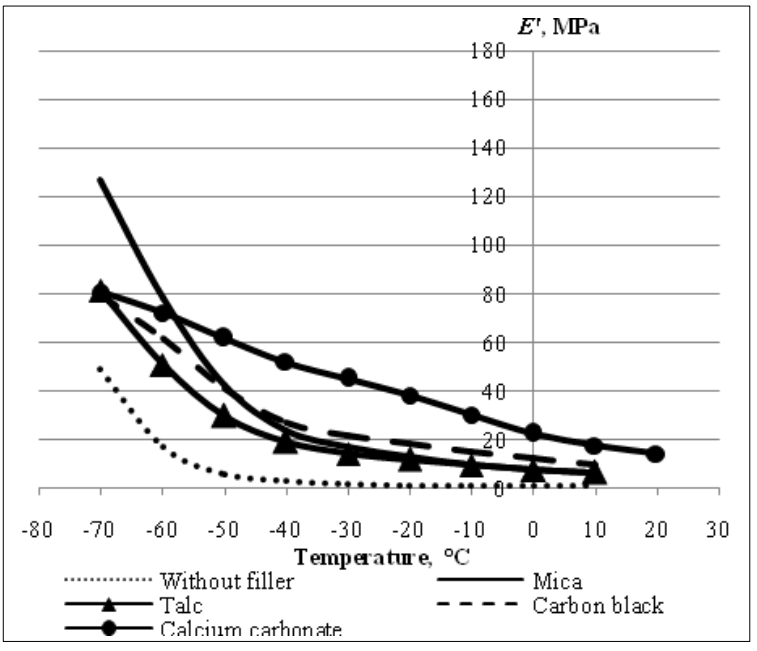

b.

Figure 3. Dynamic properties of the filled composites: a. - $\tan \delta$; b. - $E^{\prime}$

Fillers addition leads to maximum decrease of $\tan \delta$ (till $30 \%$ for talc and mica and till $50 \%$ for carbon black), however thus temperature area of effective damping extends essentially thanks to increase of $\tan \delta$ in high elastic state of a polymeric blend (Figure 3a).

The loss factor in composites with talc and mica have height of peak much more, in comparison with a maximum $\tan \delta$ composite filled with carbon black (Figure 3a). It happens because carbon black belongs to strengthening fillers. Addition of strengthening filler leads to increasing of fraction "polymerfiller", thereby causing depressing of energy dissipation and peak decreasing of $\tan \delta$ in the field of negative temperatures. In the field of $T_{g}$ dimensional network which is formed by filler and polymer, is 
enough strong and that's why energy dissipation occurs only because of a friction of polymeric fractions, unlimited by filler. At temperatures higher, than $\mathrm{T}_{\mathrm{g}}$ composite molecular friction of polymer decreases and energy dispersion occurs mainly because of own friction of system "filler-filler" and interphase friction of system "polymer-filler" as a result energy dissipation increases [14]. Thus, composite with carbon black has the greatest values of $\tan \delta$ at transferring to positive temperatures, and composites with mica and talc - in the area of negative temperatures.

We see from the graph in drawing 3 b, that all fillers with volume content of $40 \%$ raise $E^{\prime}$ of composite concerning unfilled EVA. Hydroxyl groups which are contained in structure-forming components can influene on dynamic properties of polymeric composites significantly. Mica and talc unlike carbon black contain $\mathrm{OH}^{-}$groups, therefore polar EVA can have physical interactions with surface of such fillers that reflects in changing of strength properties of a composite.

Except above considered fillers, investigation of calcium carbonate influence, as the most widespread and cheap inorganic filler, on dynamic properties of polymeric materials on the basis of EVA (see fig. 3 ) was made in this work. According to data of table 6 calcium carbonate can be referred to exicipients. However we see from the graph in drawing $3 \mathrm{a}$, that calcium carbonate addition with content of $50 \%$ in volume basis results to significant displacement of glass transition temperature (on $40^{\circ} \mathrm{C}$ ) in comparison with other exicipients. Besides, calcium carbonate addition leads to expansion of temperature area of effective damping because of increase of $\tan \delta$ in high elastic state of a polymeric blend (see fig. 3a). Thus, calcium carbonate with concentration of $50 \%$ influences on dynamic properties of a polymeric blend similar to carbon black with concentration of $40 \%$.

In compositions with polar fragments effect of polarity makes definite influence on strengthening properties of calcium carbonate [15]. Calcium carbonate is referred to polar fillers, and in our opinion, such action of calcium carbonate can be caused by occurrence of big amount of physical connections between calcium carbonate molecules and ethylene-vinyl acetate polar groups, that leads to growth of system "polymer-filler" and increase of composite viscosity, causing significant displacement of glass transition temperature and increase of a dynamic modulus of elasticity (see fig. 3b).

The revealed patterns allow to make conclusion that from the point of view of expansion of temperature area of effective damping it is the most preferable to add exicipients not less than $40 \%$ in volume basis, such as talc or mica with addition of 5-10\% of carbon black as the hardening additive, and from the point of view to reduce the price of material to use calcium carbonate with concentration of $50 \%$ in volume basis as filler.

\subsection{Influence of type and modifier content on dynamic properties of polymeric materials on the basis of ethylene-vinyl-acetate}

Received filled polymeric composites on the basis of ethylene-vinyl acetate (VA content 28\%) have wide enough interval of operating temperatures, however $\tan \delta$ in the yielded interval does not always have value above 0.3 . Therefore at the last investigation phase the method of their modification by addition of resins (alkyl phenol-formaldehyde resin or glycerol resin ester) in number of 10 - 30 m.p. was applied. Efficiency of modifiers depends on their compatibility with ethylene-vinyl acetate and is defined by solubility parametre. "Polar" dissolves in the "polar". APFR SP-1045 is polar thermoreactive resin, and esters of rosin is less polar resin (Table 7). Figures 4-5 show influence of APFR and GER on a dynamic modulus of elasticity and $\tan \delta$ of composites on the basis of EVA. 


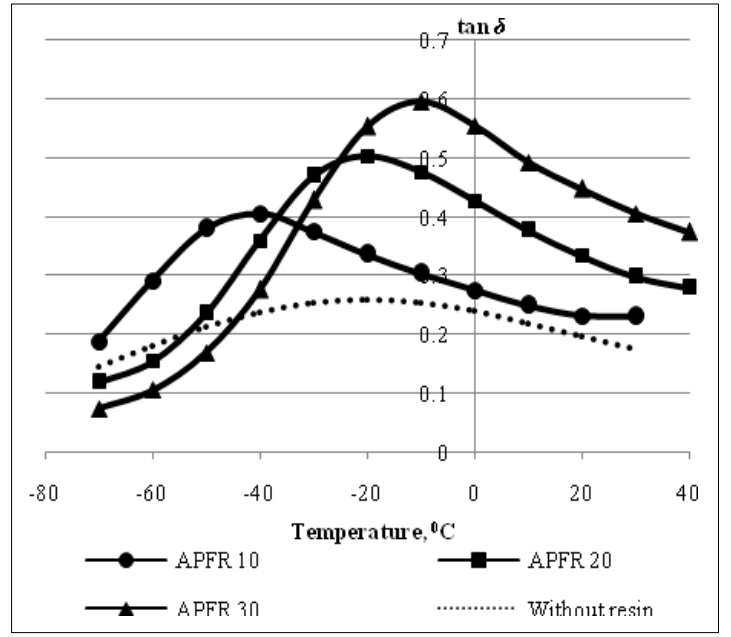

a

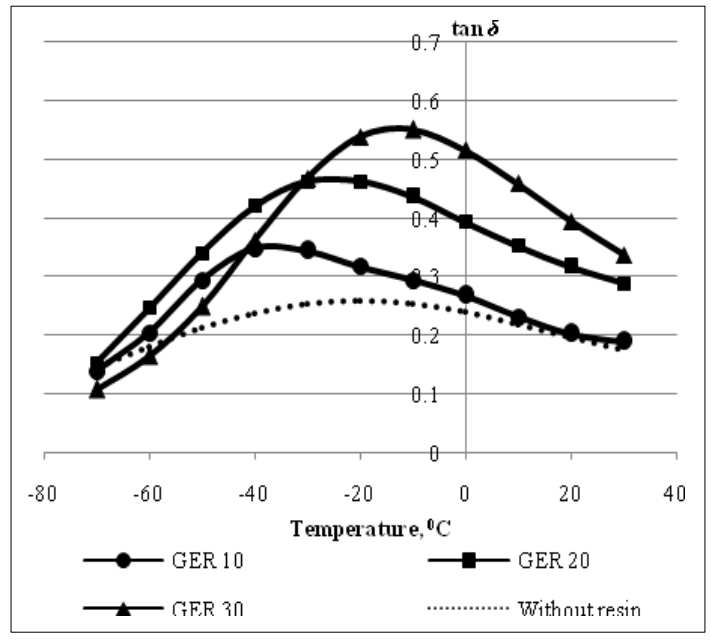

b

Figure 4. Comparison of $\tan \delta$ (oscillation frequency of $1 \mathrm{~Hz}$ ): a - APFR; b - GER
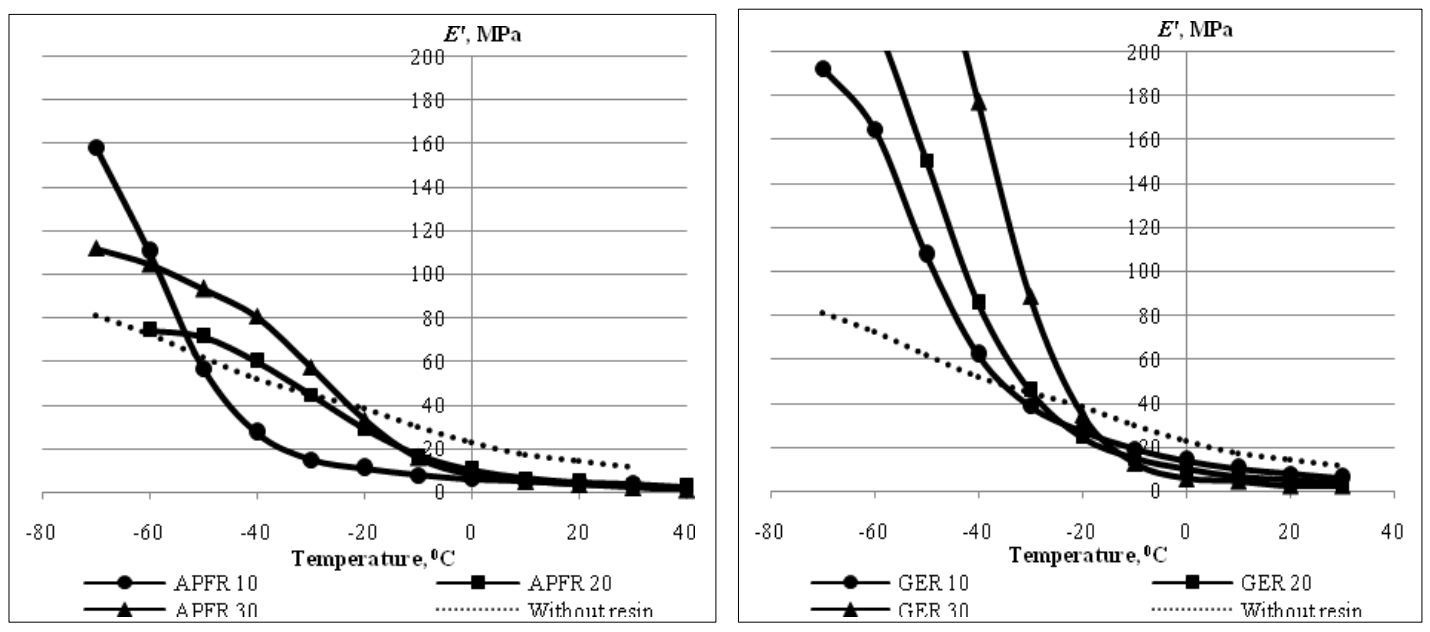

Figure 5. Comparison of $E^{\prime}$ (oscillation frequency of $1 \mathrm{~Hz}$ ): a - APFR; b - GER.

Table 7. Solubility parametre and $\mathrm{T}_{\mathrm{g}}$ of modifiers

\begin{tabular}{|c|c|c|}
\hline Name & Solubility parametre, $\left.\mathrm{MJ} / \mathrm{m}^{3}\right)^{0.5}$ & Glass transition temperature $\mathrm{T}_{\mathrm{g}},{ }^{\circ} \mathrm{C}^{1}$ \\
\hline APFR & 18.73 & 69 \\
\hline Glycerol esters of rosin & $\approx 16.38$ & 67 \\
\hline
\end{tabular}

\section{Measured by method DSC}

At addition of resins in number of $10 \mathrm{~m}$.p. the peak height of $\tan \delta$ increases and there is a displacement of glass transition temperature and, accordingly, $\tan \delta$ towards negative temperatures concerning the composite filled with calcium carbonate (see fig. 4). Apparently, small concentration of modifier as a part of a composite is the reason that small part of resin dissolves and works as plasticizer, isolating polar groups EVA.

At addition of resins in number of 20 m.p. and 30 m.p. the tendency to increase $\tan \delta$ saves, however strengthening of the modifier as a part of a composite leads to the displacement of $\mathrm{T}_{\mathrm{g}}$ towards positive temperatures (Figure 4). Increase and peak displacement of $\tan \delta$ towards positive temperatures are likely to occur because of formation of intramolecular hydrogen bonds between hydroxyl groups of resins and side groups EVA [5]. Displacement of peak of $\tan \delta$ can also be caused by the fact that glass transition temperature of resins is much more, than at initial polymer (see tab. 7) [16]. The further increase of resins share leads to decrease composite flexibility and limits its application at negative temperatures. 
Resins sharply displace $\mathrm{T}_{\mathrm{g}}$ of composites and reduce $E^{\prime}$ in a zone of high elasticity, in comparison with transitive area (Figure 5). Glass transition temperature of resins is in the area of positive temperatures (Table 7), as a result $E^{\prime}$ with increase of resin as a part of a composite decreases in the area of rubber-like materials and increases in transitive area (Figure 5). The greatest values of $E^{\prime}$ are observed at composites with esters of rosin.

The similar situation on $\tan \delta$ and $E^{\prime}$ for composites modified by resins is observed at oscillation frequency of $10 \mathrm{~Hz}$ (Figure 6, 7).

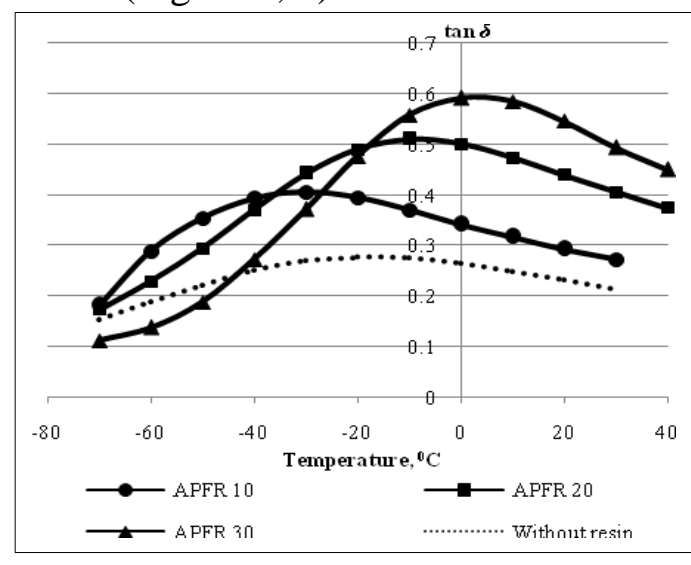

a

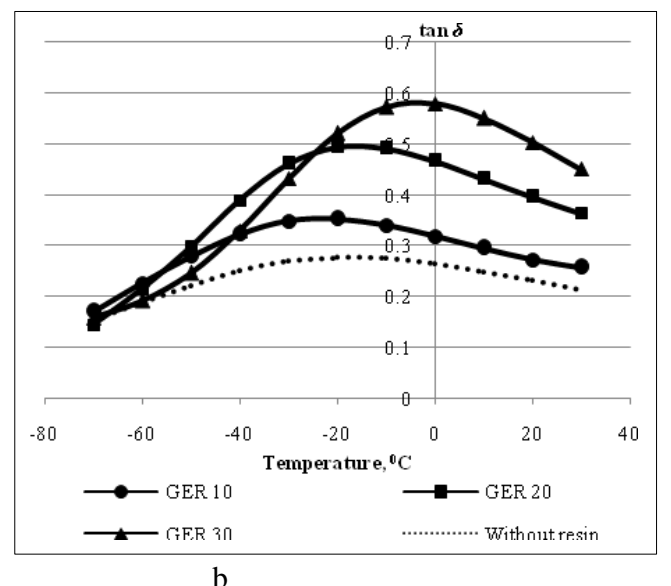

b

Figure 6. Comparison of $\tan \delta$ (oscillation frequency of $10 \mathrm{~Hz}$ ): a - APFR; b - GER

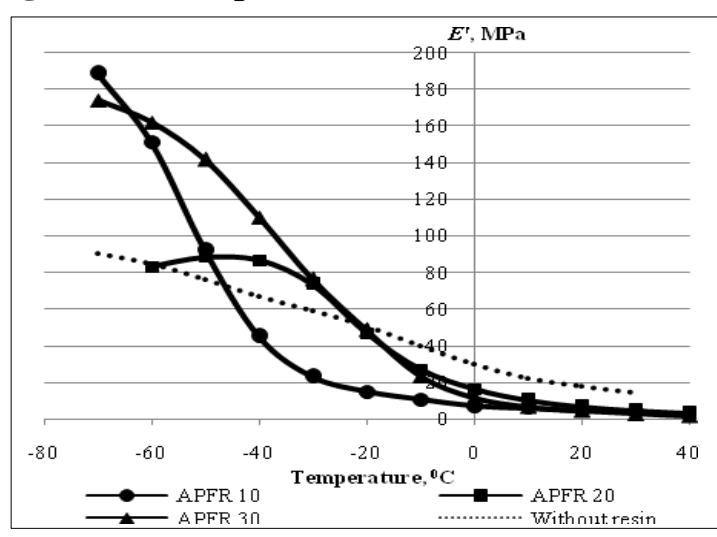

a

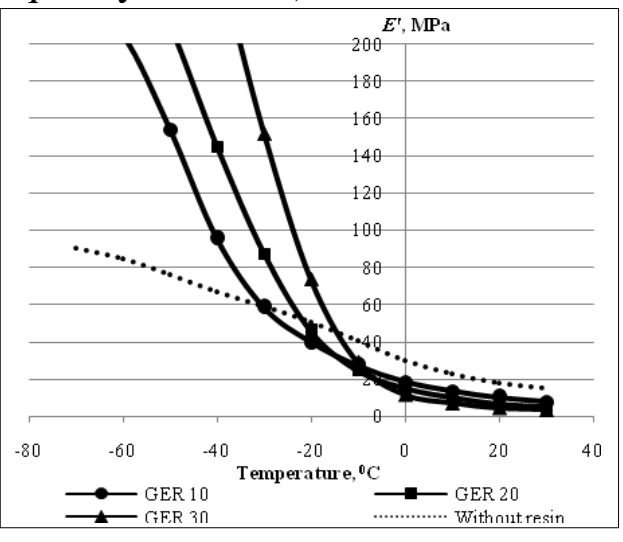

$\mathrm{b}$

Figure 7. Comparison $E^{\prime}$ (oscillation frequency of $10 \mathrm{~Hz}$ ): a - APFR; b - GER.

Besides dynamic mechanical analysis tests for cold resistance to determine a limit of working capacity of composites with resins were conducted at negative temperatures. Tests for cold resistance showed, that all samples maintain influence of negative temperatures till $-40^{\circ} \mathrm{C}$. However there are cracks on samples with addition of resin 30 m.p. at temperature decreasing till $-50^{\circ} \mathrm{C}$. It occurs because there is the biggest percent of resin content in the yielded composites, and $\mathrm{T}_{\mathrm{g}}$ is displaced towards positive temperatures concerning pure EVA the most strongly. Also the yielded composites have the greatest values of a dynamic modulus of elasticity, and they are accordingly more fragile at negative temperatures in comparison with other samples. The revealed patterns allow to make a conclusion, that the most optimal modifier is glycerol esters of rosin with content of $20 \mathrm{~m}$.p. for working out of polymeric materials with high values of $\tan \delta$, as composites with the yielded resin maintain influence of negative temperatures till $-50^{\circ} \mathrm{C}$, possess high damping properties. Also it is possible to use APFR with content of 20 m.p.as a modifier, however the yielded resin contains formaldehydes which influence on people health negatively.

On the basis of conducted researches two polymeric materials were developed which are effective in wide temperature range: 
1. Expensive material consisting of the following components: polymer - EVA 48 m.p.; plasticizer chlorine-paraffin 32 m.p.; modifier - glycerol esters of rosin with content of 20 m.p.; fillers - carbon black - 21.3 m.p.; mica or talc - 171.5 and 160.5 m.p. accordingly. The yielded material has the following properties: maximum value of $\tan \delta$ - not less than 0.45 at temperature plus $5^{\circ} \mathrm{C}$ (oscillation frequency of $10 \mathrm{~Hz}$ ); width of a temperature interval where tan $\delta$ is not less than 0.3 - from a minus 40 to plus $40^{\circ} \mathrm{C}$ (oscillation frequency of $10 \mathrm{~Hz}$ ); conditional tensile strength not less than $10 \mathrm{kgf} / \mathrm{sm}^{2}$, cold resistance to minus $50^{\circ} \mathrm{C}$.

2. Cheap material consisting of the following components: polymer - EVA 48 m.p.; plasticizer chlorine-parafin 32 m.p.; modifier - glycerol esters of rosin 30 m.p.; filler - calcium carbonate 237 m.p.. The yielded material has the following properties: maximum value of $\tan \delta$ - not less than 0.5 at temperature minus $17^{\circ} \mathrm{C}$ (oscillation frequency of $10 \mathrm{~Hz}$ ); width of a temperature interval where $\tan \delta$ is not less than 0.3 - from minus 50 to plus $40^{\circ} \mathrm{C}$ (oscillation frequency of $10 \mathrm{~Hz}$ ); conditional tensile strength not less than $10 \mathrm{kgf} / \mathrm{sm}^{2}$, cold resistance to minus $50^{\circ} \mathrm{C}$.

\title{
4. Conclusions
}

It is shown, that DOP and ChP are better combined with EVA, than industrial oil. It is revealed that addition of chlorine-paraffin to EVA leads to growth of $\tan \delta$. It is stated, that to work out damping materials on the basis of EVA it is the most preferable to use as chlorine-paraffin with content of $40 \%$ in volume basis as plasticizer. Such blends have the greatest values of loss factor at glass transition temperature. According to the next degree of plasticizer efficiency is dioctylphthalate. Use of industrial oil as plasticizer is inexpedient.

It is shown, that all fillers cause increase in a dynamic modulus of elasticity in considered temperature range. Carbon black in comparison with other fillers affects on a dynamic modulus of elasticity in highelasticity area and displaces glass transition of a binary mix EVA/plasticizer most strongly.

It is stated, that to work out damping polymeric composites on the basis of EVA which are the most effective in wide temperature range it is expedient to use two types of filler: carbon black and mica or carbon black and talc. For price reduction of a polymeric composition it is expedient to add calcium carbonate with content of $50 \%$ in volume basis.

It is found out, that addition of APFR and GER leads to increase of tan $\delta$ of a composite approximately to two times. Composites with esters of rosin addition have the greatest values of a dynamic modulus of elasticity.

Thus, to work with damping polymeric materials on the basis of EVA which have effective temperatures in a wide interval the most suitable are the following structure-forming components: ethylene-vinyl acetate with content of $60 \%$ in volume basis; plasticizer - chlorine-paraffin with volume content of $40 \%$; modifier - esters of rosin with content 20 m.p.; fillers - talc or mica with content of 40 $\%$ in volume basis with addition of carbon black wich volume content of $5 \%$, or calcium carbonate with content of $50 \%$ in volume basis.

Acknowledgements: Investigation is executed with financial support of the grant of the President of the Russian Federation (MK-1960.2018.8, the Agreement № 075-15-2019-516 from November, 15th, 2018).

This article was presented at Polymer Processing in Engineering Conference - PPE 2019, 7- 9 October 2019, Galati - Romania.

\author{
References \\ 1. SHI, X. Y., BI, W.N., ZHAO, S.G., J. Appl Polym Sci, 120, 2, 2011, p. 1121-1125. \\ 2. SHI, X.Y., BI, W.N., ZHAO, S.G., J Macromol Sci B, 50, 10, 2011, p. 1928-1938. \\ 3. SHI, X., JIA, L., MA, Y., LI, C., JMCE, 4, 2, 2016 p. 89-96. \\ 4. HE, X., QU, M., SHI, X., JMCE, 4, 3, 2016, p. 15-22.
}


5. CHANG, S., PAN, H., LIHUAN, X., CHENG Z., Adv Mat Res, 335-336, 2011, p. 120-123.

6. JIA, L., FU, G., SHI, X., J Macromol Sci, 54, 2, 2015, p. 190-202.

7. SHI, X. Y., BI, W. N., ZHAO, S. G., J. Appl Polym Sci, 124, 3, 2012, p. 2234-2239.

8. SOLOMATOV, V. I, BOBRYSHEV A.N., KHIMMLER, K.G., Polymeric composites in building, Stroyizdat, Moscow, 1988, $312 \mathrm{p}$.

9. MURTAZINA, L.I., GARIFULLIN, A.R., NIKULTSEV, I.A., FATHULLIN, R. F, AHMEDJANOVA, R. A, MILOSLAVSKIJ, D.G., GALIMZJANOVA, R. Ju., KHAKIMULLIN, Ju.N., Bulletin of Kazan technological university, 17, 9, 2014, p. 119-122.

10. DÍEZ, E., CAMACHO, J., DÍAZ, I., OVEJER, G., Polym Bull, 71, 1, 2014, p. 193-206.

11. BERSHTEJN, V. A, EGOROVA, L.M., EGOROV, V. M, SINANI, A.B. High-molecular compounds, 31, 12,1989 , p. 2482-2489.

12. LIA, X., TAN, S., LIU, G., HOCH, M., ZHA, S., J Macromol Sci, 55, nr. 5, 2016, p. 494-502.

13. KOMOVA, N.N., POTAPOV, E.E., GRUSKOV, A.D., ZAIKOV, G. E., Bulletin MITHT, 8, 1, 2013, p. 2435.

14. Jian-Hua Ma, Li-Qun Zhang, You-Ping Wu., J Macromol Sci B, 52, 8, 2013, p. 1128-1141.

15. PEROVA, M. S, GALIMOVA, L.R., KHAKIMULLIN, Ju.N., Bulletin of Kazan technological university, 6 , 2010, p. 230-235.

16. LIANG, J., CHANG, S., FENG, N., J. Appl Polym Sci, 130, 1, 2013, p. 510-515.

Manuscript received: 6.02 .2020 